\title{
NR2A Subunit Expression Shortens NMDA Receptor Synaptic Currents in Developing Neocortex
}

\author{
Alexander C. Flint, ${ }^{1}$ Ulrike S. Maisch, ${ }^{2,3}$ Jochen H. Weishaupt, ${ }^{3}$ Arnold R. Kriegstein,, ${ }^{1,2}$ and Hannah Monyer ${ }^{3}$ \\ ${ }^{1}$ Center for Neurobiology and Behavior and ${ }^{2}$ Department of Neurology, Columbia University College of Physicians and \\ Surgeons, New York, New York 10032, and ${ }^{3}$ Center for Molecular Biology, University of Heidelberg, D-69120 Heidelberg, \\ Germany
}

NMDA receptors play important roles in learning and memory and in sculpting neural connections during development. After the period of peak cortical plasticity, NMDA receptor-mediated EPSCs (NMDAR EPSCs) decrease in duration. A likely mechanism for this change in NMDA receptor properties is the molecular alteration of NMDA receptor structure by regulation of NMDA receptor subunit gene expression. The four modulatory NMDAR2A-D (NR2A-D) NMDA receptor subunits are known to alter NMDA receptor properties, and the expression of these subunits is regulated developmentally. It is unclear, however, how the four NR2 subunits are expressed in individual neurons and which NR2 subunits are important to the regulation of NMDA receptor properties during development in vivo. Analysis of NR2 subunit gene expression in single characterized neu- rons of postnatal neocortex revealed that cells expressing NR2A subunit mRNA had faster NMDAR EPSCs than cells not expressing this subunit, regardless of postnatal age. Expression of NR2A subunit mRNA in cortical neurons at even low levels seemed sufficient to alter the NMDA receptor time course. The proportion of cells expressing NR2A and displaying fast NMDAR EPSCs increased developmentally, thus providing a molecular basis for the developmental change in mean NMDAR EPSC duration.

Key words: NMDA receptors; ion channel subunit expression; single-cell RT-PCR; dot-blot hybridization; phosphorimager analysis; patch clamp; neocortical development; neocortical physiology; synaptic transmission; EPSCs
Glutamate, the principal excitatory neurotransmitter in the mammalian cerebral cortex, acts via a variety of postsynaptic receptor subtypes (Hollmann and Heinemann, 1994). The ionotropic glutamate receptor family includes NMDA receptors, AMPA receptors, and kainate receptors. The EPSC induced by glutamate results from the fast activation of non-NMDA (AMPA/kainate) receptors as well as the slower and more prolonged activation of NMDA receptors. NMDA receptors are unique among glutamate receptors in their voltage dependence and high permeability to calcium. This combination of properties is central to the role of NMDA receptors in forms of synaptic plasticity, such as long-term potentiation (LTP) (Bliss and Collingridge, 1993).

Many types of synaptic plasticity are more robust in immature animals than in adults (Crair and Malenka, 1995; Kirkwood et al., 1995). NMDAR EPSCs are longer in early postnatal life than in adulthood (Carmignoto and Vicini, 1992; Hestrin, 1992; Crair and Malenka, 1995; Takahashi et al., 1996); therefore, it has been suggested that changes in NMDA receptor efficacy might underlie critical periods for synaptic plasticity in the developing brain (Crair and Malenka, 1995). The duration of NMDAR EPSCs is thought to be determined by intrinsic receptor properties (Lester

Received Nov. 18, 1996; revised Jan. 17, 1997; accepted Jan. 23, 1997.

This work was supported by the Human Frontier Science Program (RG-53/95 B), Grant NS21223 from National Institutes of Health to A.R.K., Deutsche Forschungsgemeinschaft Grant Mo43213-1 to H.M., and Medical Scientist Training Program support from National Institutes of Health to A.C.F. We thank M. Heath, J. LoTurco, and S. Rayport for helpful comments on this manuscript. Care of animals used in these experiments was in accordance with Columbia University institutional guidelines.

Correspondence should be addressed to Dr. Arnold R. Kriegstein, Department of Neurology, Box 31, College of Physicians and Surgeons, 630 West 168th Street, New York, NY 10032.

Copyright (C) 1997 Society for Neuroscience $\quad 0270-6474 / 97 / 172469-08 \$ 05.00 / 0$ et al., 1990; Lester and Jahr, 1992) rather than the persistence of glutamate in the synaptic cleft (Clements et al., 1992). Therefore, changes in NMDAR EPSC duration are likely to result from alterations of the NMDA receptor complex itself (Hestrin, 1992; Crair and Malenka, 1995).

NMDA receptors are multimeric proteins that seem to be composed of two NR1 subunits (Behe et al., 1995) along with subunits of the NMDAR2 (NR2) family (Schoepfer et al., 1994). In situ hybridization studies (Monyer et al., 1994), RNase protection assays (Zhong et al., 1995), and immunoprecipitation experiments (Sheng et al., 1994) have demonstrated that NR2 subunit expression is regulated developmentally. In the embryonic cortical plate, only NR2B is expressed at embryonic day 19 (E19), whereas NR2D begins to be expressed by postnatal day 0 (P0, the day of birth). By P7, all four NR2 subunits are expressed in cortex at different levels (Monyer et al., 1994). These data suggest that changes in subunit expression during cortical development might regulate the function of cortical NMDA receptors. However, it is unknown to what degree multiple NR2 subunits are coexpressed in individual neurons and how cellular expression of NR2A-D subunit mRNA in vivo leads to changes in NMDA receptor function.

One approach to examine the function of individual neurotransmitter receptor subunits is to use gene-targeting techniques to remove a particular subunit from the germline (Li et al., 1994). Although this method allows for the direct manipulation of subunit expression in vivo, it has several drawbacks, including the potential for developmental compensation for the missing subunit by alterations in expression of other transcripts in the mutant (Gerlai, 1996; Lathe, 1996). Because such compensatory changes and other problems involving genetic background cannot be 
avoided, the analysis of data derived from traditional gene targeting must remain tentative. In the present study we examine the relative levels of NR2 subunit mRNA in single cells of normal animals and correlate the expression of individual subunits with the functional properties of NMDA receptors in the same cells. This approach, although by necessity correlative, has the advantage of directly linking expression of receptor subunit mRNA in normal cells with the function of receptors constructed from the products of these mRNAs.

Using this approach, we have found that cortical neurons expressing the NR2A subunit have faster NMDAR EPSCs than cells that do not express this subunit, regardless of developmental age. Low relative levels of NR2A mRNA expression seem to be sufficient to reduce the duration of NMDAR EPSCs. The proportion of cells expressing NR2A and displaying fast NMDAR EPSCs increases during postnatal development, thus providing a molecular basis for the developmental changes in EPSCs.

\section{MATERIALS AND METHODS}

Whole-cell recordings for single-cell PCR (scPCR). Whole-cell recordings in slices of neonatal rat somatosensory cortex were obtained as previously described (Blanton et al., 1989). Neocortical slices $(400 \mu \mathrm{m})$ containing the somatosensory area were made with a vibratome at $\mathrm{P} 3 / 4$ or $\mathrm{P} 8 / 9$. The bath solution contained (in $\mathrm{mM}$ ): $\mathrm{NaCl} \mathrm{124,} \mathrm{KCl} 5, \mathrm{NaH}_{2} \mathrm{PO}_{4} 1.25$, $\mathrm{MgSO}_{4} 1, \mathrm{CaCl}_{2} 2, \mathrm{NaHCO}_{3} 1.26$, and glucose $20, \mathrm{pH} 7.4$, at $25^{\circ} \mathrm{C}$ bubbled with $95 \% \mathrm{O}_{2} / 5 \% \mathrm{CO}_{2}$. Patch electrodes were filled with (in $\mathrm{mM}$ ): $\mathrm{KCl} 140$, EGTA 5, $\mathrm{MgCl}_{2} 3$, and HEPES 5, pH 7.3, at $25^{\circ} \mathrm{C}$, autoclaved for $1 \mathrm{hr}$, and filtered at $0.2 \mu \mathrm{m}$. Electrodes $(3-5 \mathrm{M} \Omega$ ) were fashioned from baked borosilicate glass $\left(220^{\circ} \mathrm{C}, 4 \mathrm{hr}\right)$. NMDAR EPSCs were evoked in the presence of $10 \mu \mathrm{M}$ 6,7-dinitroquinoxaline-2,3-dione (DNQX) to block non-NMDA receptors, $50 \mu \mathrm{m}$ bicuculline methiodide to block $\mathrm{GABA}_{\mathrm{A}}$ receptors, and $40 \mu \mathrm{M}$ glycine to prevent antagonism of the NMDA receptor glycine site by DNQX (Kim et al., 1995). Stimulation $(150 \mu \mathrm{sec}$, $50-400 \mu \mathrm{A}$ ) was applied by bipolar Formvar-coated nichrome wire electrodes placed in layer 4. A minimum interstimulus interval of $90 \mathrm{sec}$ was used because of the sensitivity of PSCs in young neurons to higher rates of stimulation (Kriegstein et al., 1987). Whole-cell currents and potentials were recorded and digitized with the use of a computercontrolled patch-clamp amplifier (EPC-9, ALA, Westbury, NY). Individual NMDAR EPSC decays were fit with a single exponential function, using PulseFit software (List), and the time constants from fits to three to five EPSCs evoked in each cell were averaged for analysis. Single exponentials were found empirically to best fit our data in all cells analyzed. Whereas NMDAR EPSCs in adult animals and older developing animals are best fit by a double exponential function (Lester et al., 1990), several groups previously have found that NMDAR EPSCs in early neonatal neurons were best fit by single exponentials (Carmignoto and Vicini, 1992; Hestrin, 1992; Crair and Malenka, 1995). Voltage-dependent magnesium block of the evoked NMDAR EPSC was observed in all cells, regardless of age (3-to 10-fold lower amplitude current measured at -70 vs $-30 \mathrm{mV}$ ). Confirmation that EPSCs were NMDAR-mediated was obtained by reversible blockade of responses with the NMDA receptor antagonist D-2-amino-5-phosphonopentanoate (AP-5 $100 \mu \mathrm{M}, n=6$ ).

Single-cell reverse-transcription PCR (RT-PCR). Single-cell RT-PCR was performed as previously described (Lambolez et al., 1992; Geiger et al., 1995), with modifications pertaining to the quantitative evaluation of products (see below). Reverse-transcription of single-cell RNA was performed as previously described (Geiger et al., 1995). Coamplification of NR2A-D subunits was performed by nested hot-start PCR. The sequences of the primers for the first round of PCR were NR2 $5^{\prime}, 5^{\prime}$ GGGTGATGATGTT(TC)GT(GC)ATG-3'; NR2 $\quad 3^{\prime}-1, \quad 5^{\prime}-\mathrm{T}(\mathrm{GC})$ CTC(TC)TGGATCATGAAGGC-3'. The cycling parameters for the first amplification were $94^{\circ} \mathrm{C}$ for $5 \mathrm{~min}, 5$ cycles $\left(94^{\circ} \mathrm{C}, 30 \mathrm{sec} ; 48^{\circ} \mathrm{C}, 30 \mathrm{sec}\right.$; ramp to $72^{\circ} \mathrm{C}, 70 \mathrm{sec}$ and $\left.72^{\circ} \mathrm{C}, 40 \mathrm{sec}\right)$, followed by 35 cycles $\left(94^{\circ} \mathrm{C}, 30\right.$ sec; $53^{\circ} \mathrm{C}, 30 \mathrm{sec} ; 72^{\circ} \mathrm{C}, 40 \mathrm{sec}$ ) at $72^{\circ} \mathrm{C}$ for $10 \mathrm{~min}$. One microliter of the first-round PCR product was reamplified in a second PCR by using the same $5^{\prime}$ primer and a nested $3^{\prime}$ primer: NR2 3'-2, (5'-ATGAC(AC) GC(AG)AAGAAGG-CCCA-3'). The second PCR was performed according to the following program: $80^{\circ} \mathrm{C}$, for $5 \mathrm{~min}, 35$ cycles $\left(94^{\circ} \mathrm{C}, 30 \mathrm{sec}\right.$; $53^{\circ} \mathrm{C}, 30 \mathrm{sec} ; 72^{\circ} \mathrm{C}, 40 \mathrm{sec}$ ) and $72^{\circ} \mathrm{C}$ for $10 \mathrm{~min}$. Both PCR reactions contained $20 \mathrm{~mm}$ Tris- $\mathrm{HCl}, \mathrm{pH} 8.4,50 \mathrm{~mm} \mathrm{KCl}, 0.4 \mu \mathrm{M}$ of each primer, and 2.5 U of Taq DNA polymerase (Life Technologies, Gaithersburg, MD). The first PCR reaction contained $1.25 \mathrm{~mm} \mathrm{MgCl}_{2}$ and $0.15 \mathrm{~mm}$ dNTPs $(+0.05 \mathrm{~mm}$ dNTPs from the RT reaction), and the second PCR reaction contained $1.5 \mathrm{~mm} \mathrm{MgCl}_{2}$ and $0.2 \mathrm{~mm}$ dNTPs. As previously described (Geiger et al., 1995), PCR conditions and different primer pairs were tested extensively to guarantee that under conditions used in these experiments NR2 subunits were amplified with a comparable efficiency (see Results). Controls were performed for each single-cell PCR experiment by advancing electrodes into the bath solution or tissue and using its contents for RT-PCR; in no cases were false amplifications obtained.

Ratiometric analysis of PCR products by dot-blot hybridization. PCR products of expected size on agarose gel electrophoresis (247 bp) were phenol chloroform-extracted, ethanol-precipitated, and resuspended in $\mathrm{dH}_{2} \mathrm{O}$. A serial dilution of each PCR product was dotted onto four different nitrocellulose membranes, each containing a serial dilution of one of the four "NR2 standards" (50-12.5 ng). Standards were obtained by cloning PCR fragments ( $244 \mathrm{bp}$ ) of each NR2 subunit into an M13 vector. The PCR primers used for cloning were similar to those used for the first scPCR reaction but included an EcoRI site in the $5^{\prime}$ primer and a PstI site in the $3^{\prime}$ primer. Primers for cloning had the following sequences: 5' NR2 cloning primer, 5'-GCGAATTCTGGGTGATGATGTT(TC)GT(GC)ATG-3'; 3' NR2 cloning primer, 5'-GGACTG CAGACAGC(AG)AAGAAGGCCCACAC-3'. PCR products and standards were denatured with $\mathrm{NaOH}$, neutralized with $\mathrm{NH}_{4} \mathrm{Ac}$, and dotted in triplicate for each concentration point by a dot-blot apparatus (Schleicher \& Schuell, Keene, NH). The membranes were hybridized with radiolabeled NR2 subunit-specific oligonucleotide probes (oligo NR2A, 5'-AGAAGGCCCGTGGGAGCTTTCCCTTTGGCTAAGTTTC-3'; oligo $N R 2 B, 5 '$-GGGCCTCCTGGCTCTCTGCCATCGGCTAGG CACCTGTTGTAACCC-3'; oligo NR2C, 5'-TGGTCCACCAGGTTTCTTGCCCTTGGTGAGGTTCTGGTTGTA-GCT-3'; oligo NR2D, 5' CGTGGCCAG-GCTTCGGTTATAGCCCACAGGACTGAGGT-3') (Monyer et al., 1994) overnight at $37^{\circ} \mathrm{C}$, washed with $0.2 \times \operatorname{SSC}\left(55^{\circ} \mathrm{C}\right)$, and exposed in a phosphorimager (Bio-Rad, Richmond, CA) for analysis on a Macintosh computer (Molecular Analyst and Microsoft Excel software). Standard procedures for probe labeling, hybridization, and posthybridization washing were used as described in laboratory manuals (Ausubel, 1989). Relative percentages of each subunit amplified were calculated from the intensity of hybridization signal from dotted sample relative to the intensity of hybridization signal from dotted plasmid standard (details provided in Results). Linearity of the dot-blot technique was confirmed in each experiment for both standard and samples (see Results). Data for subunit percentages and EPSC duration are presented as mean \pm SEM unless otherwise indicated.

\section{RESULTS}

\section{Cell population and single-cell RT-PCR}

To determine the molecular basis for developmental changes in NMDA receptor efficacy in somatosensory cortex (S1), we used single-cell RT-PCR (Lambolez et al., 1992; Jonas et al., 1994) to detect NR2A-D subunit expression in physiologically characterized neurons. Whole-cell recordings were made in slices of rat somatosensory cortex at postnatal ages $\mathrm{P} 3 / 4$ or P8/9. To avoid potential cell type-specific differences in subunit expression (Jonas et al., 1994; Geiger et al., 1995), we used only excitatory regularspiking (RS) (McCormick et al., 1985) layer 2/3 neurons in this study (Fig. $1 A, E$ ). After characterization of intrinsic firing pattern and NMDAR EPSCs (Fig. 1E,F), cytoplasmic harvest was performed. Reverse-transcription of single-cell mRNA was followed by PCR designed to coamplify all four NR2 subunits (see below). Amplified products of expected size (Fig. $1 B$ ) were analyzed by dot-blot hybridization, using probes specific to each NR2 subunit (Fig. 1C,D). The technique of dot-blot analysis of single-cell PCR products was developed in the present study as a more accurate and less time-consuming method of ratiometric PCR product analysis, as compared with the methods previously used (Geiger et al., 1995; Lambolez et al., 1996) (see below and Materials and Methods). We obtained detailed morphology of the neurons under study by using dye-labeling techniques in conjunction with scPCR. In 10 cells from which successful amplifications of NR2 
A

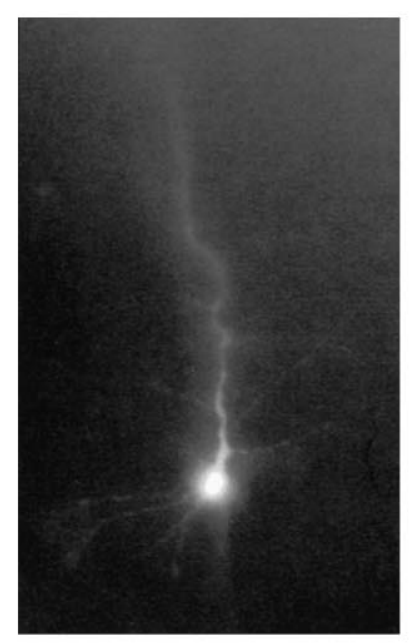

B
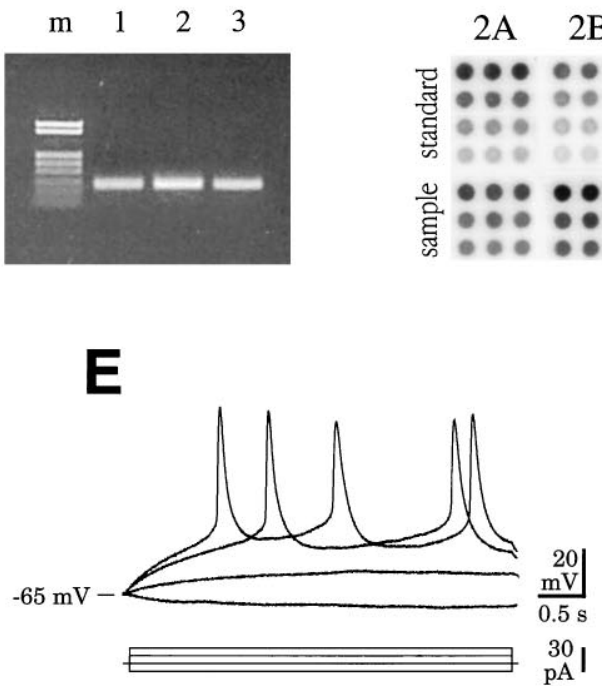

D
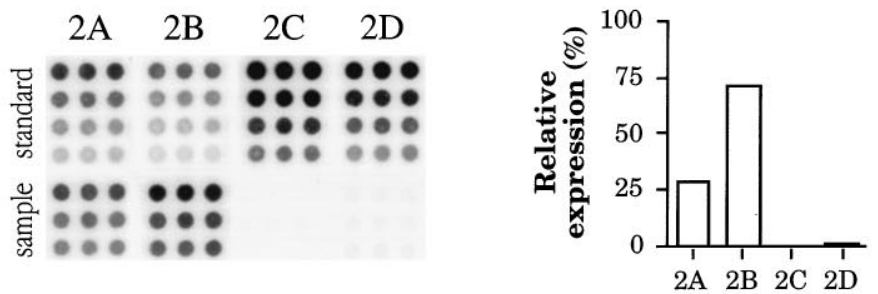

NMDAR2 subunit

Figure 1. Single-cell RT-PCR performed on neonatal cortical neurons from slices of rat somatosensory cortex. $A$, Lucifer yellow-filled pyramidal neuron from which physiological and molecular data were obtained [layer 2/3, postnatal day 4 (P4) S1 slice]. $B$, Ethidium bromide-stained gel electrophoresis of products obtained by RT-PCR for NR2A-D subunits on cytoplasmic material harvested from physiologically characterized neurons. Lane 1, RT-PCR product from the neuron shown in $A$; lanes 2-3, RT-PCR products from a P3 and P8 neuron, respectively; $m$, marker (pRK7/HinfI). All RT-PCR products used for analysis were of expected size, $247 \mathrm{bp}$. $C$, Composite image of the dot blots of a RT-PCR product (shown in $B$, lane 3 ) from a P8 neuron hybridized with ${ }^{32} \mathrm{P}$-labeled probes specific to $N R 2 A, 2 B, 2 C$, and $2 D$ subunits. Standard, cDNAs for the respective NR2A-D subunit dotted in triplicate at each of four serial dilutions; sample, three serial dilutions of the PCR product shown in $B$, lane 3, on each membrane. $D$, Graph of relative expression levels of the four NR2 subunits for the dot blot shown in $C$, as determined by phosphorimager analysis normalized for signal strength of each standard (see Results and Fig. 2). E, Intrinsic firing properties of a regular-spiking neuron (McCormick et al., 1985) recorded at P4 in response to current injection. $F$, Average of three NMDAR EPSCs evoked in a layer $2 / 3$ cell at $\mathrm{P} 4$ by stimulation of afferent fibers in layer 4 . $V_{\mathrm{H}}$, Holding potential of the voltage clamp; $\tau$, time constant of a single exponential fit to the decay phase of the NMDAR EPSC. Cells were held at $-30 \mathrm{mV}$ to relieve the voltage-dependent magnesium block of the NMDA receptor (Nowak et al., 1984).

subunit cDNA were obtained, Lucifer yellow was included in the pipette to obtain morphological data. All cells stained with Lucifer yellow in this series were pyramidal neurons (Fig. $1 A$ ). These data, along with the RS firing pattern observed in all recorded cells, confirm that our cell population consisted mainly of excitatory neurons (McCormick et al., 1985).

\section{Linearity of the dot-blot technique and nonpreferential amplification of NR2 subunits}

The method we previously used for the analysis of single-cell PCR products allows for semiquantitative analysis of relative subunit abundance (Geiger et al., 1995), but this method, which relies on cloning of PCR products and transformation, is arduous and time-consuming. Therefore, we developed a more efficient and more accurate method for semiquantitative scPCR product analysis that relies on dot-blot hybridization with subunit-specific probes and phosphorimager analysis.

Several control experiments were performed to demonstrate that dot-blot hybridization analysis of single-cell RT-PCR products could provide reliable semiquantitative data concerning NR2 subunit expression. First, the linearity of the dot blot for each of the four standards was tested. In preliminary experiments, five to eight serial dilutions of each of the four NR2 standards were analyzed by dot-blot hybridization and phosphorimager analysis; in all cases the relationship between known standard concentration and phosphorimager units was linear, with correlation coefficients of $r=0.997$ to $r=0.999$. In every scPCR experiment, four serial dilutions of each standard were dotted to derive linear standard curves to compare relative abundance of the four NR2 subunits in each PCR product. Figure $2 A$ shows an example of one membrane from a single-cell PCR dot-blot experiment. In this example the membrane was dotted with serial dilutions of the NR2B standard and three scPCR amplification samples and then probed with radiolabeled oligo NR2B. Figure $2 B$ demonstrates the method of normalizing to the hybridization intensity of the standard. A linear standard curve $(r=0.999)$ based on the four serial dilutions of the NR2B standard was used to derive the amount of NR2B DNA present in a PCR amplification sample on the basis of the hybridization signal detected from the sample, in this case sample 3 (boxed in Fig. $2 A$; gray arrow in Fig. $2 B$ ). The same procedure was followed for each of the four membranes, thereby allowing for calculation of the relative abundance of each NR2 subunit in a given amplification.

To achieve nonpreferential amplification of NR2 subunits during PCR, we tested a series of PCR primers in conserved regions of NR2A-D sequence, as previously described for GluRA-D primers (Jonas et al., 1994; Geiger et al., 1995). To demonstrate that the primers used in the present experiments nonpreferentially amplify all four NR2 subunits, we mixed different combinations and ratios of three subunits and used $10 \mathrm{ng}$ of these mixtures for PCR amplification. Before mixing and PCR amplification, the plasmids were digested with BstEII to produce a linear template. Table 1 illustrates the relative percentages (in mean \pm SD) detected after amplification in independent experiments in which the subunits NR2A, NR2B, and NR2C were mixed at ratios of 9:1:1, 1:9:1, 1:1:9, and 1:1:1, and the subunits NR2A, NR2C, and NR2D were mixed at ratios of 9:1:1, 1:9:1, and 1:1:9. The overall mean distortion of subunit percentage after amplification in these experiments was $\sim 10 \%$ ( $n=19$ amplifications). In addition, we 
A

NR2B

standard sample 1 sample 2 sample 3

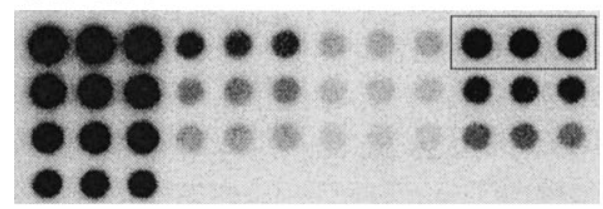

B

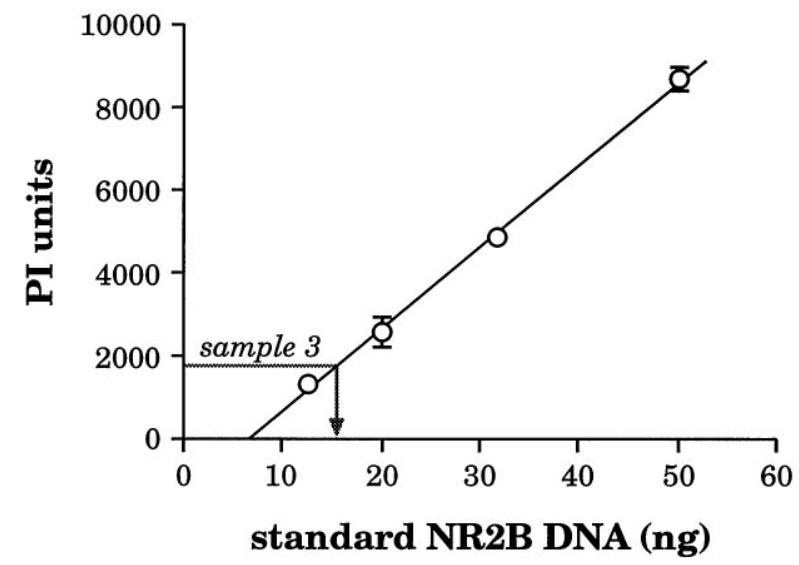

Figure 2. Ratiometric analysis of coamplified PCR products by dot-blot hybridization. $A$, Example of the dot-blot results from a single membrane dotted in triplicate with four serial dilutions of the NR2B standard and three serial dilutions of each of three PCR amplifications (samples 1-3). The membrane was probed with a radiolabeled oligonucleotide probe specific to the NR2B subunit (oligo NR2B) and exposed in a phosphorimager. $B$, Method of normalizing to the standard in each membrane. Using the phosphorimager data from the NR2B membrane shown in $A$, we constructed a linear standard curve from the four triplicate serial dilutions of the standard [shown as mean $\pm \mathrm{SD}$; phosphorimager (PI) units for each dilution, $r=0.999$ ]. Using this standard curve, we could determine the amount of NR2B DNA present in a given PCR product, as shown for sample 3 (boxed in $A$; gray arrow in $B$ ). The relative percentage of each subunit present in a given sample then could be calculated from the amount detected in this way on each of the four membranes.

tested for cross-hybridization of each subunit-specific probe with the other three subunits, which was in all cases $<5 \%$. On the basis of these data, we used an estimate of $10 \%$ as the background level of detection in our analysis of dot-blot data.

\section{Developmental decrease in NMDAR EPSC duration}

NMDAR EPSC duration in S1 neurons decreased substantially from $\mathrm{P} 3 / 4$ to $\mathrm{P} 8 / 9$. Figure $3 A$ shows superimposed examples of average NMDAR EPSCs observed in a P4 cortical neuron $(\tau=$ $295 \mathrm{msec})$ and a P9 cortical neuron $(\tau=130 \mathrm{msec})$. The mean decay of NMDAR EPSCs evoked at P3/4 (262.8 $\pm 20.8 \mathrm{msec}$; mean \pm SEM, $n=30)$ was significantly longer than that of the NMDAR EPSCs evoked at P8/9 (146 $\pm 9.1 \mathrm{msec} ; n=41)$ (Fig. $3 B, p<0.0005$; two-tailed Student's $t$ test). Similar decreases in NMDAR EPSC duration have been observed in other neural populations in the developing brain, including layer 4 of both somatosensory cortex (Crair and Malenka, 1995) and visual cortex (Carmignoto and Vicini, 1992), the superior colliculus (Hestrin, 1992), and the cerebellum (Takahashi et al., 1996). To investigate whether changes in the relative expression levels of NR2 subunits in individual neurons underlie the observed developmental changes in NMDA receptor efficacy, we characterized NMDAR
EPSCs from neurons in layer $2 / 3$ and performed single-cell RTPCR for NR2A-D subunits.

\section{Single-cell expression of NR2 subunit mRNA}

At both P3/4 and P8/9, we found that the NR2B subunit was expressed above the estimated background level of our assay ( $>10 \%$, see above) in almost every cell ( $n=30$ of 32; Fig. $4 C)$. In contrast, very few cells expressed significant relative amounts of NR2C or NR2D subunits. NR2C was encountered in only one cell at P3/4 and one cell at P8/9, but in these cells NR2C was expressed at high levels (91 and $76 \%$ of total NR2 expression, respectively). NR2D was detected only at P3/4, in 2 of 12 cells (32 and $73 \%$ of total NR2 expression, respectively).

A more dramatic developmentally regulated expression pattern was observed for the NR2A subunit. NR2A was encountered above background levels $(>10 \%)$ in only 2 of 12 cells at P3/4 (Fig. $4 A$ ). By P8/9, however, a majority of cells expressed NR2A $(n=$ 12 of 20 , Fig. $4 B$ ). At both ages when NR2A was expressed, it was almost always coexpressed with NR2B ( $n=13$ of 14). This observed developmental increase in NR2A expression by single layer $2 / 3$ neurons suggests a molecular basis for the developmental decrease in the mean duration of NMDAR EPSCs. In heterologous expression systems, NR2A expressed with NR1 produces a fast-decaying current in response to rapid application of glutamate, as compared with the slower decay of NR2B, NR2C, or NR2D expressed with NR1 (Monyer et al., 1994). Although it is not known how native expression of the NR2 subunits with NR1 in vivo affects NMDAR EPSC time course or how coexpressed NR2 subunits might interact, it is likely that expression of NR2A in neurons would lead to more rapid NMDAR EPSCs.

\section{NR2A mRNA expression and NMDAR EPSC time course}

Consistent with a role of NR2A in decreasing the duration of NMDAR EPSCs, analysis of neurons in both age groups revealed that cells expressing NR2A had significantly shorter NMDAR EPSCs than cells not expressing NR2A. Neurons expressing $<10 \%$ NR2A (mean of $2.1 \pm 0.5 \%$ NR2A) had a mean NMDAR EPSC decay time constant of $256.2 \pm 22.1 \mathrm{msec}$, whereas neurons expressing $>10 \%$ NR2A (mean of $46.2 \pm 6.3 \%$ NR2A) had a mean NMDAR EPSC decay time constant of $116.3 \pm 4.9 \mathrm{msec}$ (Fig. 5A, difference significant at $p<0.0005$; two-tailed Student's $t$ test). The substantial decrease in NMDAR EPSC duration seen in cells expressing NR2A supports the hypothesis that NR2A expression is responsible for the developmental decrease in NMDAR EPSC duration.

The developmental change in NMDAR EPSC duration could, however, be attributable to another developmentally regulated process rather than the noted change in NR2A expression. To define the role of NR2A more clearly, we took advantage of the heterogeneity of NR2A expression detected in single neurons at each age. At P3/4 two groups of cells could be discerned on the basis of NR2A expression levels, one with high NR2B expression and background levels of NR2A expression ( $n=10$ of 12, Fig. $4 A_{1}$ ) and the other with high NR2A expression and low NR2B expression ( $n=2$ of 12 , Fig. $4 A_{2}$ ). Similarly, one group at P8/9 expressed NR2A along with NR2B ( $n=12$ of 20, Fig. $4 B_{1}$ ), and another had background levels of NR2A expression with high NR2B expression $\left(n=8\right.$ of 20 , Fig. $\left.4 B_{2}\right)$. Comparison of the two groups at $\mathrm{P} 8 / 9$ revealed that cells that expressed NR2A had shorter NMDAR EPSCs than cells that did not express NR2A. Cells at P8/9 not expressing NR2A (mean $2.1 \pm 0.5 \%$ NR2A) had 


\begin{tabular}{|c|c|c|c|c|c|}
\hline \multicolumn{3}{|c|}{ Input subunit percentages } & \multicolumn{3}{|c|}{ Amplified subunit percentages } \\
\hline$\% \mathrm{NR} 2 \mathrm{~A}$ & $\%$ NR2B & $\% \mathrm{NR} 2 \mathrm{C}$ & $\%$ NR2A & $\%$ NR2B & $\% \mathrm{NR} 2 \mathrm{C}$ \\
\hline 81.8 & 9.1 & 9.1 & $63.8 \pm 2.7(3)$ & $16.9 \pm 2.2(3)$ & $19.3 \pm 0.6(3)$ \\
\hline 9.1 & 81.8 & 9.1 & $19.7 \pm 0.9(3)$ & $59.8 \pm 1.4(3)$ & $20.5 \pm 2.1(3)$ \\
\hline 9.1 & 9.1 & 81.8 & $19.8 \pm 0.4(3)$ & $16.0 \pm 3.0(3)$ & $64.2 \pm 3.3(3)$ \\
\hline 33.3 & 33.3 & 33.3 & $38.0 \pm 0.5(3)$ & $31.4 \pm 3.3(3)$ & $30.7 \pm 2.9(3)$ \\
\hline$\%$ NR2A & $\% \mathrm{NR} 2 \mathrm{C}$ & $\%$ NR2D & $\%$ NR2A & $\% \mathrm{NR} 2 \mathrm{C}$ & $\%$ NR2D \\
\hline 81.8 & 9.1 & 9.1 & $76.1 \pm 0.4(2)$ & $19.1 \pm 0.5(2)$ & $4.8 \pm 0.1(2)$ \\
\hline 9.1 & 81.8 & 9.1 & $4.7 \pm 0.3(3)$ & $92.3 \pm 0.5(3)$ & $3.0 \pm 0.3(3)$ \\
\hline 9.1 & 9.1 & 81.8 & $9.8 \pm 0.9(2)$ & $23.3 \pm 0.9(2)$ & $66.9 \pm 1.8(2)$ \\
\hline
\end{tabular}

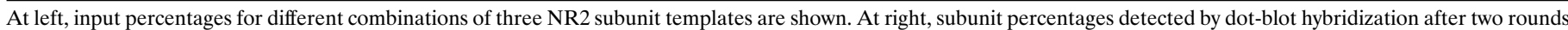
of PCR amplification are given as mean \pm SD for the number of experiments indicated in parentheses.

a mean NMDAR EPSC decay time constant of $193.5 \pm 18.6 \mathrm{msec}$, whereas cells at P8/9 expressing NR2A (mean $40.9 \pm 5.9 \%$ NR2A) had a mean NMDAR EPSC decay time constant of $117.5 \pm 5.7 \mathrm{msec}$ (Fig. $5 B$, difference significant at $p<0.0005$; two-tailed Student's $t$ test). If changes in NR2A expression are a principal factor in shortening the NMDAR EPSC, one also would expect that the few cells expressing NR2A at P3/4 would have faster NMDAR EPSCs. Indeed, the two cells encountered at P3/4 with high NR2A expression (mean $78.0 \pm 13.0 \%$ NR2A; Fig. $4 A_{2}$ ) had very rapid NMDAR EPSCs for this age (decay time constants of 104.5 and $113 \mathrm{msec}$, as compared with a mean of $306.3 \pm 28.5$ msec for cells at P3/4 not expressing NR2A). Therefore, NR2A expression in single cortical neurons seems to regulate the time course of the NMDAR EPSC.

\section{DISCUSSION}

We have analyzed the expression of NMDA receptor NR2A-D subunit mRNA in single neurons of developing somatosensory cortex and found that single-cell NR2A expression seems to reduce significantly the time course of NMDAR EPSCs. Our finding that NR2A expression is an important factor in regulating
NMDAR EPSC duration in normal animals is consistent with recent findings in transgenic mice with a targeted deletion of the mouse homolog of NR2A, NR $\epsilon 1$. In the absence of NR2A $(\mathrm{NR} \epsilon 1)$, the developmental decrease in NMDAR EPSC duration normally found in cerebellar neurons is blunted significantly (Takahashi et al., 1996). Our finding that NR2A expression decreases NMDAR EPSC duration in neurons from normal animals suggests that the blunted changes in NMDAR EPSC time course in the $N R \epsilon 1$ null mutant are indeed the direct result of the lack of $\mathrm{NR} \epsilon 1$ and not the result of unknown compensatory changes in the mutant. Therefore, these different experimental approaches are complementary and together suggest that the NR2A subunit plays a critical role in regulating NMDAR EPSC time course during development.

Our data also suggest that NR2A may play a dominant role in determining NMDAR EPSC duration. When NR2A was expressed, it was almost always coexpressed with NR2B ( $n=13 / 14$, see above). This observation is supported by the finding that NR2A subunit protein coimmunoprecipitates with NR2B by the second postnatal week in rat cortex (Sheng et al., 1994). Expres-
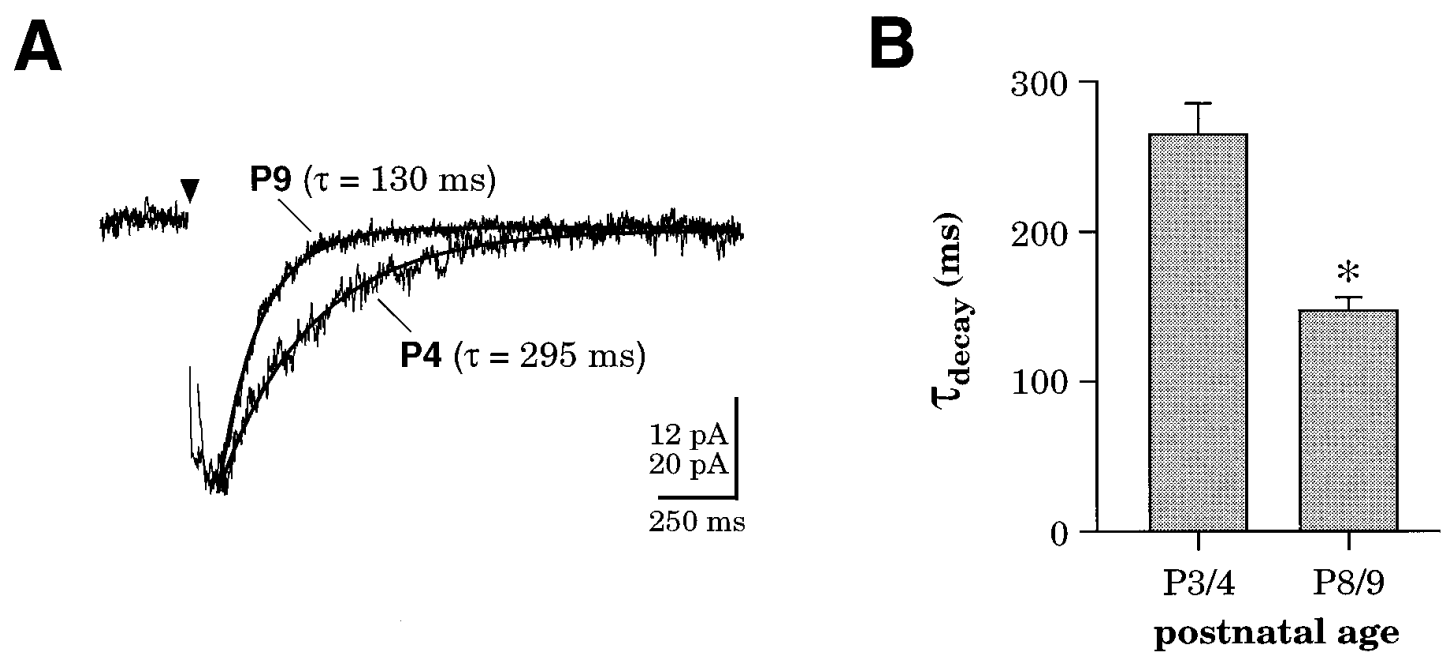

Figure 3. Duration of NMDAR EPSCs decreases during postnatal development in layer $2 / 3$ neurons of somatosensory cortex. $A$, Averaged NMDAR EPSCs from a $P 4$ and $P 9$ neuron, each fit with a single exponential. Each trace is an average of three responses, and both cells were held at $-30 \mathrm{mV}$. The amplitude of the $P 9$ trace is normalized to the amplitude of the $P 4$ trace; vertical scale bar represents $12 \mathrm{pA}$ for the $P 4$ trace and $20 \mathrm{pA}$ for the $P 9$ trace. $B$, Decrease in the mean \pm SEM decay time constant of exponentials fit to NMDAR EPSCs at $P 3 / 4(n=30)$ and $P 8 / 9(n=41)$. ${ }^{*}$ Difference significant at $p<0.0005$; two-tailed Student's $t$ test. 
P3/4

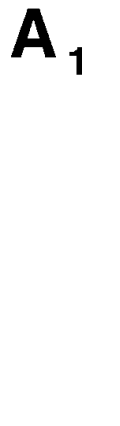

\section{$\mathbf{A}_{2}$}
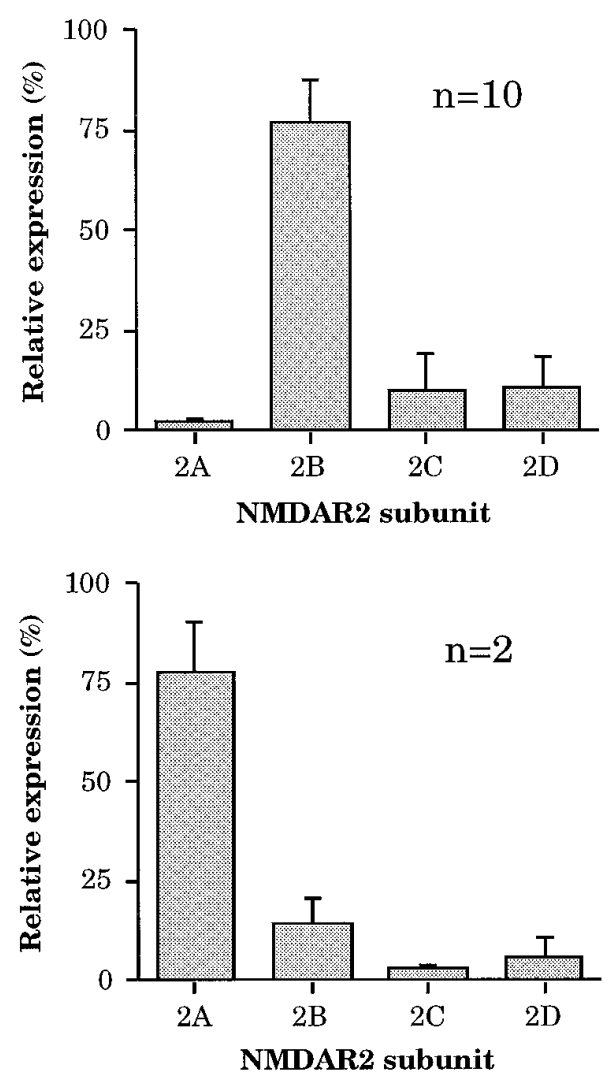

P8/9

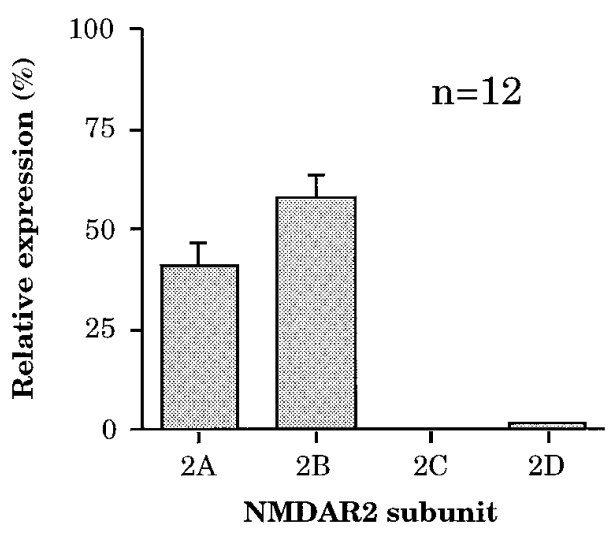

$\mathbf{B}_{2}$

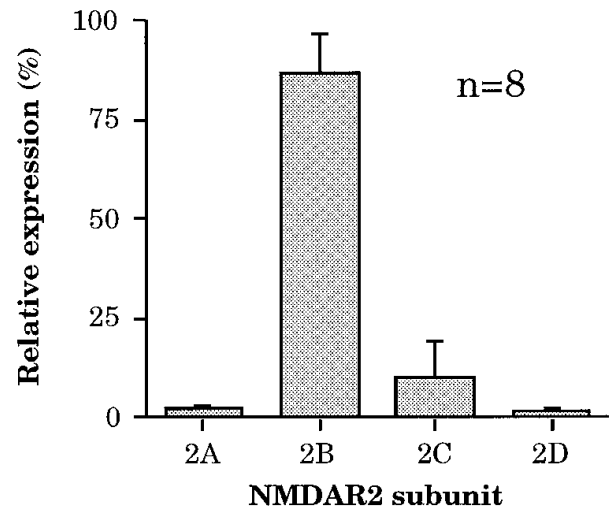

C
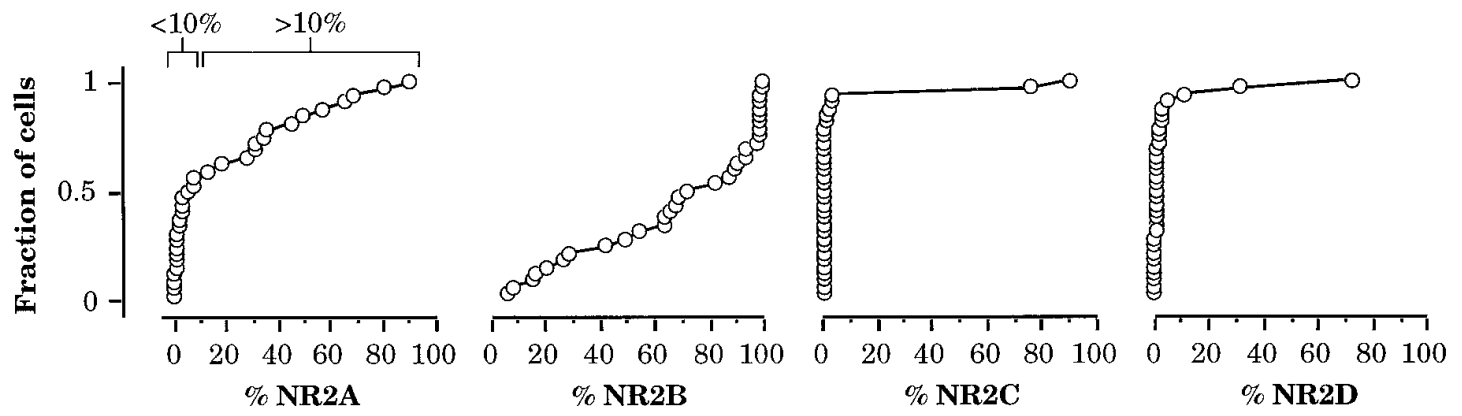

Figure 4. Age-dependent patterns of single-cell NR2 subunit expression. $A_{1}, A_{2}$, Two groups could be discerned at $P 3 / 4$ on the basis of NR2A subunit expression. $A_{1}$, The majority of cells at $P 3 / 4$ did not express NR2A above background but expressed high relative levels of NR2B $(n=10) . A_{2}$, Two of 12 cells at $P 3 / 4$ did express relatively high levels of NR2A. $B_{1}, B_{2}$, Two groups were apparent at $P 8 / 9$ on the basis of NR2A expression. $B_{1}$, A majority of cells $(n=12)$ expressed NR2A along with NR2B. $B_{2}$, Eight of 20 cells expressed no significant NR2A and expressed high relative levels of NR2B. $C$, Cumulative histogram of percentage of relative expression of each NR2 subunit obtained from the 32 neurons in both age groups, demonstrating that relative $N R 2 A$ and $N R 2 B$ subunit expression is highly regulated in this population (left 2 panels). In contrast, very few cells expressed $N R 2 C$ or $N R 2 D$ (right 2 panels).

sion of NR2A above background levels imparted a more rapid NMDAR EPSC to the neurons in our sample, but the relationship between relative NR2A expression and the NMDAR EPSC decay time constant was nonlinear (Fig. 5C). This relationship suggests that a low threshold of cellular NR2A expression may be sufficient to affect the duration of NMDAR EPSCs. This hypothesis is supported by the observation that no cells encountered with $>10 \%$ NR2A expression displayed slow NMDAR EPSCs. Cells measured as expressing $<10 \%$ NR2A have a much slower mean NMDAR EPSC duration than those expressing $>10 \%$ NR $2 A$ but display a range of NMDAR EPSC durations, because individual cells measured as expressing $<10 \%$ NR2A are within the background noise level of our assay and likely include some that expressed sufficient NR2A to produce faster NMDAR EPSCs.

The apparent dominance of NR2A on the NMDAR EPSC time course does not imply that NR2A expression acts as a simple binary "switch" in developing neurons. Our data suggest only that relatively low levels of NR2A mRNA, compared with NR2B mRNA, in neurons can influence the NMDAR EPSC. A graded effect of NR2A expression on NMDAR EPSC time course might 
A

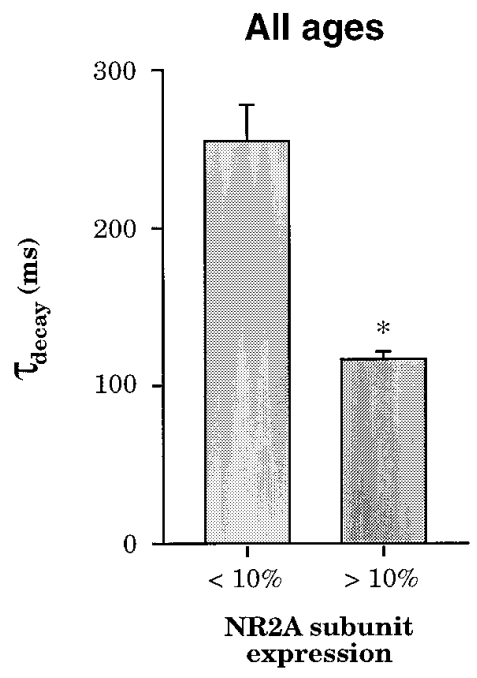

B

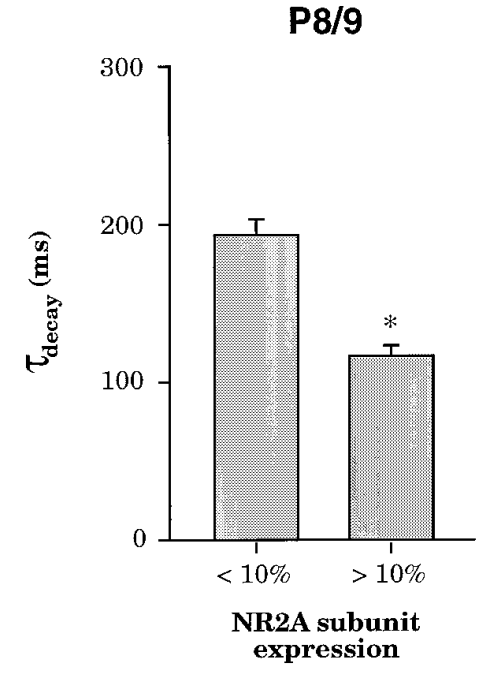

C

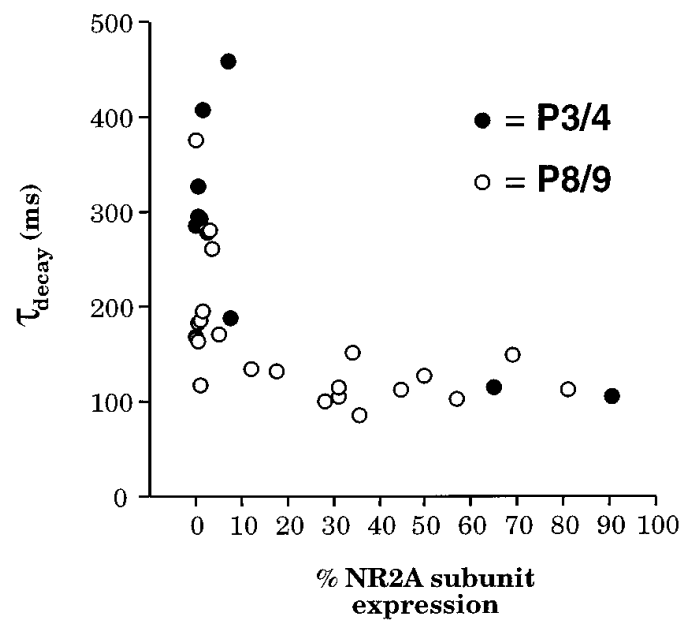

Figure 5. NR2A subunit expression decreases the time course of NMDAR EPSCs. $A$, Neurons in both age groups $(P 3 / 4$ and $P 8 / 9)$ with lower than background NR2A expression ( $<10 \%$; mean $2.1 \pm 0.5 \%$ NR2A) had a longer mean NMDAR EPSC decay time constant than neurons expressing NR2A above background (mean $46.2 \pm 6.3 \% \mathrm{NR} 2 \mathrm{~A}) . B$, Neurons at the same age $(P 8 / 9)$ that did not express NR2A $(<10 \%$; mean $2.1 \pm 0.5 \%$ NR2A) had a longer mean NMDAR EPSC decay time constant than neurons that did express NR2A (mean $40.9 \pm 5.9 \%$ NR2A). * Difference significant at $p<0.0005$; two-tailed Student's $t$ test. $C$, Relationship between relative NR2A subunit expression and NMDAR EPSC decay time constant, demonstrating a low apparent threshold of NR2A expression required to decrease NMDAR EPSC duration. Each point represents data from a single cell at either P3/4 (black circles) or $P 8 / 9$ (white circles).

be observed among cells expressing low levels of NR2A (0-30\%) if more precise measurements of relative NR2 subunit abundance were possible. Indeed, a graded effect would be predicted by previous studies that have analyzed NMDAR EPSC time course as a function of age in settings in which the changes occur more gradually over the course of development (Carmignoto and Vicini, 1992; Hestrin, 1992). Evidence that an individual receptor subunit can act in a dominant, but graded, manner to determine receptor and ion channel properties has been provided for AMPA receptors (Schoepfer et al., 1994; Geiger et al., 1995) in which the GluR-B subunit has dominant effects on gating and conductance.

Previous studies have shown that the developmental decrease in NMDAR EPSC duration is activity-dependent (Carmignoto and Vicini, 1992). Therefore, it is possible that developing neurons shorten their NMDAR EPSC duration in response to activity by upregulating NR2A mRNA. In fact, recent evidence supports the notion that NR2A can be controlled by neuronal activity. Depolarization of cerebellar granule cells in culture has been shown to lead to a significant upregulation of NR2A subunit expression (Vallano et al., 1996). In addition, NR2A subunit upregulation by cultured cortical neurons is significantly attenuated by serum deprivation, whereas NR2B levels are unaffected (Zhong et al., 1994). However, it remains to be seen whether the normal developmental pattern of neocortical NR2A expression in vivo is activity-dependent.

NMDA receptors are thought to influence patterned connectivity in developing sensory systems by translating synchronous inputs into increases in synaptic strength (Constantine-Paton et al., 1990; Bliss and Collingridge, 1993). Changes in NMDA receptor efficacy have, therefore, been proposed as a mechanism establishing critical periods for plasticity in neocortex (Fox et al., 1992; Crair and Malenka, 1995). NMDA receptors are required for the organization of neural connections during development in several settings, including the formation of whisker representation "barrelettes" in the trigeminal brainstem nuclei, plasticity of S1 barrel size, the segregation of eye-specific inputs to the tectum of tadpoles with a supernumerary eye, and the normal development of ocular dominance in the visual cortex of kittens (Cline et al., 1987; Bear et al., 1990; Schlaggar et al., 1993; Li et al., 1994).

In the present study we have used analysis of gene expression in single electrophysiologically characterized cortical neurons to examine the molecular mechanisms underlying developmental changes in NMDA receptor efficacy. To facilitate analysis of single-cell RT-PCR products, we have developed a novel dot-blot hybridization procedure that is more rapid and accurate than previously established methods. Using these techniques, we find that NR2A expression shortens the time course of NMDAR EPSCs in developing cortical neurons. Additionally, NR2A seems to have a low threshold of relative expression above which it exerts a dominant influence on the NMDAR EPSC time course. Our present findings demonstrate a molecular basis for the modification of NMDA receptor efficacy during early neocortical development in normal animals and suggest that NR2A subunit expression may be one way in which synaptic and anatomical plasticity are regulated developmentally.

\section{REFERENCES}

Ausubel FM (1989) Current protocols in molecular biology. New York: Greene Publishing and Wiley-Interscience.

Bear MF, Kleinschmidt A, Gu QA, Singer W (1990) Disruption of experience-dependent synaptic modifications in striate cortex by infusion of an NMDA receptor antagonist. J Neurosci 10:909-925.

Behe P, Stern P, Wyllie DJ, Nassar M, Schoepfer R, Colquhoun D (1995) Determination of NMDA NR1 subunit copy number in recombinant NMDA receptors. Proc R Soc Lond [Biol] 262:205-213.

Blanton MG, Lo Turco JJ, Kriegstein AR (1989) Whole cell recording from neurons in slices of reptilian and mammalian cerebral cortex. J Neurosci Methods 30:203-210.

Bliss TV, Collingridge GL (1993) A synaptic model of memory: longterm potentiation in the hippocampus. Nature 361:31-39. 
Carmignoto G, Vicini S (1992) Activity-dependent decrease in NMDA receptor responses during development of the visual cortex. Science 258:1007-1011.

Clements JD, Lester RA, Tong G, Jahr CE, Westbrook GL (1992) The time course of glutamate in the synaptic cleft. Science 258:1498-1501.

Cline HT, Debski EA, Constantine-Paton M (1987) $N$-methyl-Daspartate receptor antagonist desegregates eye-specific stripes. Proc Natl Acad Sci USA 84:4342-4345.

Constantine-Paton M, Cline HT, Debski E (1990) Patterned activity, synaptic convergence, and the NMDA receptor in developing visual pathways. Annu Rev Neurosci 13:129-154.

Crair MC, Malenka RC (1995) A critical period for long-term potentiation at thalamocortical synapses. Nature 375:325-328.

Fox K, Daw N, Sato H, Czepita D (1992) The effect of visual experience on development of NMDA receptor synaptic transmission in kitten visual cortex. J Neurosci 12:2672-2684.

Geiger JR, Melcher T, Koh DS, Sakmann B, Seeburg PH, Jonas P, Monyer H (1995) Relative abundance of subunit mRNAs determines gating and $\mathrm{Ca}^{2+}$ permeability of AMPA receptors in principal neurons and interneurons in rat CNS. Neuron 15:193-204.

Gerlai R (1996) Gene targeting in neuroscience: the systemic approach. Trends Neurosci 19:188-189.

Hestrin S (1992) Developmental regulation of NMDA receptormediated synaptic currents at a central synapse. Nature 357:686-689.

Hollmann M, Heinemann S (1994) Cloned glutamate receptors. Annu Rev Neurosci 17:31-108.

Jonas P, Racca C, Sakmann B, Seeburg PH, Monyer H (1994) Differences in $\mathrm{Ca}^{2+}$ permeability of AMPA-type glutamate receptor channels in neocortical neurons caused by differential GluR-B subunit expression. Neuron 12:1281-1289.

Kim HG, Fox K, Connors BW (1995) Properties of excitatory synaptic events in neurons of primary somatosensory cortex of neonatal rats. Cereb Cortex 5:148-157.

Kirkwood A, Lee HK, Bear MF (1995) Co-regulation of long-term potentiation and experience-dependent synaptic plasticity in visual cortex by age and experience. Nature 375:328-331.

Kriegstein AR, Suppes T, Prince DA (1987) Cellular and synaptic physiology and epileptogenesis of developing rat neocortical neurons in vitro. Brain Res 431:161-171.

Lambolez B, Audinat E, Bochet P, Crepel F, Rossier J (1992) AMPA receptor subunits expressed by single Purkinje cells. Neuron 9:247-258.

Lambolez B, Ropert N, Perrais D, Rossier J, Hestrin S (1996) Correlation between kinetics and RNA splicing of alpha-amino-3-hydroxy-5- methylisoxazole-4-propionic acid receptors in neocortical neurons. Proc Natl Acad Sci USA 93:1797-1802.

Lathe R (1996) Mice, gene-targeting, and behaviour: more than just genetic background. Trends Neurosci 19:183-186.

Lester RA, Jahr CE (1992) NMDA channel behavior depends on agonist affinity. J Neurosci 12:635-643.

Lester RA, Clements JD, Westbrook GL, Jahr CE (1990) Channel kinetics determine the time course of NMDA receptor-mediated synaptic currents. Nature 346:565-567.

Li Y, Erzurumlu RS, Chen C, Jhaveri S, Tonegawa S (1994) Whiskerrelated neuronal patterns fail to develop in the trigeminal brainstem nuclei of NMDAR1 knockout mice. Cell 76:427-437.

McCormick DA, Connors BW, Lighthall JW, Prince DA (1985) Comparative electrophysiology of pyramidal and sparsely spiny stellate neurons of the neocortex. J Neurophysiol 54:782-806.

Monyer H, Burnashev N, Laurie DJ, Sakmann B, Seeburg PH (1994) Developmental and regional expression in the rat brain and functional properties of four NMDA receptors. Neuron 12:529-540.

Nowak L, Bregestovski P, Ascher P, Herbet A, Prochiantz A (1984) Magnesium gates glutamate-activated channels in mouse central neurones. Nature 307:462-465.

Schlaggar BL, Fox K, O'Leary DD (1993) Postsynaptic control of plasticity in developing somatosensory cortex. Nature 364:623-626.

Schoepfer R, Monyer H, Sommer B, Wisden W, Sprengel R, Kuner T, Lomeli H, Herb A, Kohler M, Burnashev N (1994) Molecular biology of glutamate receptors. Prog Neurobiol 42:353-357.

Sheng M, Cummings J, Roldan LA, Jan YN, Jan LY (1994) Changing subunit composition of heteromeric NMDA receptors during development of rat cortex. Nature 368:144-147.

Takahashi T, Feldmeyer D, Suzuki N, Onodera K, Cull-Candy SG, Sakimura K, Mishina M (1996) Functional correlation of NMDA receptor $\epsilon$ subunit expression with the properties of single-channel and synaptic currents in the developing cerebellum. J Neurosci 16:4376-4382.

Vallano ML, Lambolez B, Audinat E, Rossier J (1996) Neuronal activity differentially regulates NMDA receptor subunit expression in cerebellar granule cells. J Neurosci 16:631-639.

Zhong J, Russell SL, Pritchett DB, Molinoff PB, Williams K (1994) Expression of mRNAs encoding subunits of the $N$-methyl-D-aspartate receptor in cultured cortical neurons. Mol Pharmacol 45:846-853.

Zhong J, Carrozza DP, Williams K, Pritchett DB, Molinoff PB (1995) Expression of mRNAs encoding subunits of the NMDA receptor in developing rat brain. J Neurochem 64:531-539. 